\title{
QUALITATIVE UNCERTAINTY PRINCIPLES FOR THE GENERALIZED HARTLEY TRANSFORM
}

\author{
HATEM MEJJAOLI
}

Abstract. We consider a new differential-difference operator $\Lambda_{s}$ on the real line. We study the harmonic analysis associated with this operator. Next, we prove various mathematical aspects of the qualitative uncertainty principles, including Hardy's, Morgan's, Cowling-Price's and its variants, Beurling's, Gelfand-Shilov's, Miyachi's theorems for the generalized Hartley transform associated to the operator $\Lambda_{s}$.

Mathematics subject classification (2010): 35C80,51F15,43A32.

Keywords and phrases: Generalized Hartley transform, Hardy's type theorem, Morgan's theorem, Cowling-Price's theorem, Beurling's theorem, Miyachi's theorem.

\section{REFERENCES}

[1] S. Ben FARAH AND K. MoKNI, Uncertainty principle and $L^{p}-L^{q}$-sufficient pairs on non compact real symmetric spaces, Comptes Rendus de I'Academie des Sciences Paris, Série I, 336, (2003), 889892.

[2] R. N. BRacewell, The Hartley Transform, Oxford University Press, New York, 1986.

[3] A. Beurling, The collect works of Arne Beurling, Birkhäuser, Boston, 1989, 1-2.

[4] W. R. Bloom And Z. XU, Fourier transforms of Schwartz functions on Chébli-Trimèche hypergroups, Mh. Math. 125 1998, 89-109.

[5] A. Bonami, B. Demange And P. Jaming, Hermite functions and uncertainty principles for the Fourier and the windowed Fourier transforms, Rev. Mat. Iberoamericana, 19 (2002), 22-35.

[6] M. G. Cowling AND J. F. PRICE, Generalizations of Heisenberg inequality, Lecture Notes in Math., 992, Springer, Berlin (1983), 443-449.

[7] R. Daher, T. Kawazoe And H. Mejuaoli, A generalization of Miyachi's theorem, J. Math. Soc. Japon. V., 61, no. 2 (2009), 551-558.

[8] M. Eguichi, S. Koizumi And K. Kumahara, An $L^{p}$ version of Hardy theorem for the motion group, J. Austral. Math. Soc. Serie A., 68, no. 2 (2000), 55-67.

[9] A. Fitouni, Heat polynomials for a singular differential operator on $(0, \infty)$, J. Constructive approximation, V., 5, no. 2 (1989), 241-270.

[10] L. Gallardo And K. TRimèche, An $L^{p}$ version of Hardy's theorem for the Dunkl transform, J. Austr. Math. Soc. Volume 77, Issue 03, (2004), 371-386.

[11] J. M. Gelfand And N. YA. Vilenkin, Les distributions, tome 4, Application de l'analyse harmonique, Dunod, Paris, 1967.

[12] G. H. HARDY, A theorem concerning Fourier transform, J. London Math. Soc., 8 (1933), 227-231.

[13] R. V. L. HARTLEY, A more symmetrical Fourier analysis applied to transmission problems, Proc IRE. 30, (1942) 144-150.

[14] L. HöRMANDER, A uniqueness theorem of Beurling for Fourier transform pairs, Ark. För Math., 2 (1991), 237-240.

[15] H. MeJjaoli, An analogue of Beurling-Hörmander's theorem associated with Dunkl-Bessel operator, Fract. Calc. Appl. Anal. 9 (2006), no. 3, 247-264.

[16] H. MejJaOli AND M. SAlhi, Uncertainty principles for the Weinstein transform, Czechoslovak Mathematical Journal (2011), Volume 61, Issue 4, 941-974. 
[17] A. MiYACHI, A generalization of theorem of Hardy, Harmonic Analysis Seminar held at Izunagaoka, Shizuoka-Ken, Japon 1997, 44-51.

[18] G. W. Morgan, A note on Fourier transforms, J. London Math. Soc., 9 (1934), 188-192.

[19] S. PARUi AND R. P. SARKAR, Beurling's theorem and $L^{p}-L^{q}$ Morgan's theorem for step two nilpotent Lie groups, Publ. Res. Inst. Math. Sci 44, (2008), 1027-1056.

[20] S. K. RAY AND R. P. SARKAR, Cowling-Price theorem and characterization of heat kernel on symmetric spaces, Proc. Indian Acad. Sci. (Math. Sci.), 114 (2004), 159-180.

[21] L. SchWARTZ, Théorie des distributions, Hermann, Paris, 1966.

[22] K. TRIMÈCHE, Inversion of the J.L. Lions transmutation operators using generalized wavelets, Applied and Computational Harmonic Analysis, 4 (1997), 97-112.

[23] K. TRImÈche, Positivity of the transmutation operators associated with a Cherednik type operator on the real line, Advances in Pure and Applied Mathematics, Volume 3, Issue 4, (2013), 361-376.

[24] K. TRIMÈche, The transmutation operators relating to a Dunkl Type operator on $\mathbb{R}$ and their positivity, Mediterr. J. Math. May 2015, Volume 12, Issue 2, 349-369.

[25] S. B. YaKUbovich, Uncertainty principles for the Kontorovich-Lebedev transform, Math. Model. Anal., 13 (2) (2008), 289-302. 